\title{
Estimation of undrained shear strength of fine grained soils from cone penetration resistance
}

\author{
Abdul Karim Mohamad Zein ${ }^{*}$
}

\author{
*Correspondence: \\ karimzein2000@yahoo.com \\ Head of Geotechnical \\ Engineering Department, \\ Building and Road Research \\ Institute (BRRI), University \\ of Khartoum, Gamaa Avenue, \\ Khartoum, Sudan
}

\begin{abstract}
Background: Many previous authors have proposed empirical methods for the evaluation of undrained shear strength $S_{u}$ of soft to stiff saturated cohesive soils from CPT cone resistance $q_{c}$ data. Published works are rare on this topic for the cases of unsaturated and overconsolidated clays and therefore further studies are needed to study the $S_{u}$ versus $q_{c}$ relationship for such soils. This paper investigates the $q_{c}-S_{u}$ correlation for Sudanese fine grained soils taking into account the soil type, moisture condition and stress history effects.
\end{abstract}

Methods: Database pertaining to many soil samples representing low to high plastic clays and silts collected from thirty different Sudanese states was used in this study for analysis. The $S_{u}$ values were determined from laboratory by the UU triaxial test method on undisturbed soil samples taken from adjacent borings and the CPT was performed by a mechanical adhesion jacket cone type.

Results: The $S_{u}$ values varied from 30.3 to $460 \mathrm{kPa}$ in the clay soils and from 16 to $252 \mathrm{kPa}$ in the silt soils with average values of 129 and $91 \mathrm{kPa}$ respectively. The consistency of most clay soils could be described as firm to very stiff with few soft and hard samples. The values of empirical cone factor $N_{k}$ were determined for the soil types considered and found to vary over a wide range of 35.1 to 55.6 with average values of 37.5 for clay soils and 44.1 for silt soils.

Discussion: A rigorous analysis of soil database was performed to model the $S_{u}-q_{c}$ relationship taking into account the effects of plasticity index and overconsolidation ratio soil parameters. The cone factor $N_{k}$ values determined were analyzed and compared to those experienced in previous studies from different countries. The study results revealed that for a given soil the $N_{k}$ is not a simple constant but depends on several factors such as moisture condition and degree of stiffness prevailing in the field during testing. The $N_{k}$ values obtained are in close agreement with and confirm the 35 figure reported in previous studies for highly plastic clay and silt soils. The average $N_{k}$ values obtained are much higher than those reported in several countries for normally consolidated soft to firm saturated cohesive soils but are lower than values found in few studies for hard and overconsolidated soils. Interpretation of the CPT and $\mathrm{S}_{u}$ database is different for saturated and unsaturated soils which makes comparison of the $N_{k}$ values difficult.

Conclusions: A reliable correlation cannot be directly developed between $S_{u}$ and $q_{c}$ for soils with different types and characteristics as both variables are influenced by 
several factors. The effects of soil type, moisture condition and stress history should be considered in studying the $a_{c}-S_{u}$ relationship. Reliable empirical relationships have been developed to estimate $S_{u}$ from CPT $a_{c}$ data for Sudanese clay and silt soils of different OCR values.

Keywords: Undrained strength, CPT, Cone resistance, Clays, Silts, Stress history, OCR

\section{Background}

The cone penetration test "CPT" is widely used as a site investigation tool for the classification and characterization of soils because there is a theoretical basis for interpretation of its data. The advantages which make the CPT superior to other techniques are; the method is relatively quick, simple and economical; the test equipment can be easily mobilized to site; the test data provide a continuous data record for the whole investigated soil depth; the method facilitates testing soils in their natural condition thus avoiding the soil sampling and handling effects and it provides repeatable and reliable data, i.e. not operator dependent.

The development and application of the CPT method has yielded considerable amount of valuable information on the characteristics and behavior of soils in many countries. Numerous empirical and semi-empirical methods have been proposed to classify soils and estimate important parameters such as shear strength evaluation, settlement predictions and the design of foundations for engineering structures from CPT data.

One of the main CPT method applications is to evaluate the undrained shear strength $\left(S_{u}\right)$ of fine grained soils, the subject of this paper. Various authors have proposed empirical methods for estimating the undrained strength of cohesive soils from the CPT cone resistance $\left(q_{c}\right)$ using an empirical cone factor $\left(N_{k}\right)$ defined as the $q_{c} / S_{u}$ ratio. The vast majority of previous research works on the $S_{u}$-CPT relationship were carried out on soft to stiff saturated cohesive soils using electrical cones with or without pore water pressure measurements. In general, low $N_{k}$ values were found by many authors for soft and normally consolidated soils whereas relatively high $N_{k}$ values were reported in few studies for some tropical and overconsolidated cohesive soils. Published research works on the $q_{c}-S_{u}$ relationship are rare for the cases of unsaturated and overconsolidated cohesive soils which are predominant in arid and semi-arid regions. Further studies are needed to compare the $N_{k}$ values and examine the validity of correlation methods proposed for saturated and normally consolidated soils.

The CPT was introduced to Sudan in 1977 and since then has successfully been applied in many research projects to classify and characterize local soils and in the design of various foundation types. Considerable experience and knowledge have been gained in understanding the CPT method and its value in the evaluation of local soils behavior.

Empirical relationships were proposed in two previous studies for estimating $S_{u}$ directly from measured $q_{c}$ values for some local clay and silt soils but no consideration was given to soil type and stress history effects. The present study was meant to contribute in this particular research area for Sudanese fine grained soils of different stress history and moisture conditions. The primary study objective is to determine the $N_{k}$ values 
for cohesive soils tested and investigate the possibility of developing a sound $S_{u}-q_{c}$ correlation which takes into account the soil type and overconsolidation ratio effects. A short review of the relevant published research studies on the applications of the CPT for undrained shear strength evaluation is presented hereunder.

\section{Evaluation of soil undrained shear strength from CPT data}

The soil undrained shear strength can be evaluated from CPT on the basis of theoretical solutions using the bearing capacity equation [1, 2], cavity expansion theory [3], analytical and numerical methods [4], or strain path theory [5]. Empirical relationships have been proposed by various authors for estimating the undrained shear strength of cohesive soils $\left(S_{u}\right)$ from the CPT cone resistance $\left(q_{c}\right)$. Most of these relationships were based on the bearing capacity theory wherein $S_{u}$ was directly related to the net cone resistance $\left(q_{c}-\sigma^{\prime} \sigma_{v}^{\prime}\right)$ according to the equation:

$$
S_{u}=\frac{\left(q_{c}-\sigma_{v}^{\prime}\right)}{N_{c}}
$$

$N_{c}$ is a theoretical cone factor and $\sigma^{\prime} v$ is the effective overburden pressure at a given soil depth. The above expression became the theoretical basis of later empirical or semiempirical correlations but in order to distinguish them from the theoretical solutions the empirical cone factor is denoted by $N_{k}$ as follows:

$$
S_{u}=\frac{\left(q_{c}-\sigma^{\prime} v\right)}{N_{k}}
$$

Researchers from different countries used the above equation to determine the $N_{k}$ values that match the nature and conditions of soils in their regions. Examples of the proposed $N_{k}$ values are given in Table 1.

It has been recognized from previous studies that $N_{k}$ is not a simple constant but varies significantly from site to site depending on several factors. The most important factors include the type, shape and roughness of the cone, the physical and mechanical soil properties and the testing methods used to determine soil shear strength [6]. Therefore, care should be taken in applying the relationships for soil types and conditions different from those for which they were proposed.

Table 1 Typical values of cone factor $\mathbf{N}_{k}$ for various soil types

\begin{tabular}{lll}
\hline Soil types and source & $\mathbf{N}_{\boldsymbol{k}}$ range & References \\
\hline Alluvial clays, Malaysia & $12-19$ & Abdel Rahman [24] \\
Various NC soft clays, Germany & $8-29$ & Gebreselassie [20] \\
Quaternary clay and clay stone, Germany & 89.3 & Gebreselassie [20] \\
Klang Clay, Indonesia & $5-12$ & Chen [25] \\
Stiff fissured clays (general) & $11-30$ & Terzaghi et al. [26] \\
High plastic clay and silts, Sudan & $32-39$ & Ismail and Zein [21] \\
Alluvial clay and silt soils, Sudan & $34-62$ & Hassan [17] \\
Soft to firm saturated clays, Nigeria & $34.2-57.2$ & Otoko and Isoteim [22] \\
Busan clay, Korea & $7-20$ & Rémai [10] \\
Soft Holocene clays, Hungary & $12-32$ & Sanglerat [19] \\
Various soil types (worldwide) & $5-70$ & \\
\hline
\end{tabular}


In the studies carried out to investigate the factors affecting $N_{k}$ values, more attention had been given to the soil type and stress history parameters expressed in terms of the plasticity index $P I$ [7], and over-consolidation ratio, OCR [8]. A strong linear relationship was recently reported by Novobasi [9] between $N_{k}$ and $P I$ whereas no correlation was found between the two variables for the soils tested in other regions [10].

As for the OCR, it has been indicated that a reliable correlation can be established between $S_{u}$ and $\left(q_{c}-\sigma^{\prime} \sigma_{v}^{\prime}\right)$ if the insitu stress state and stress history are considered in data analysis. Various relationships have been proposed to directly evaluate the $O C R$ of a given soil type either from CPT profiles or from the undrained soil strength $\left(S_{u}\right)$. For example, [Mayne and Kemper [11] proposed the following relationship between $O C R$ and the normalized net cone resistance $\left(q_{c}-\sigma^{\prime} \sigma_{v}^{\prime}\right) / \sigma^{\prime} \sigma_{v}^{\prime}$ :

$$
O C R=\frac{k_{t}\left(q_{c}-\sigma_{v}^{\prime}\right)}{\sigma_{v}^{\prime}}
$$

$k_{t}$ is an empirical parameter ranging between 0.12 and 0.5 for most of the database tested by mechanical cones and its value seems to be site and soil type dependent. A similar relationship was reported for some British clay soils [12] but with a different $k_{t}$ value. [13] proposed the graphical relationship shown in Fig. 1 between $\left(q_{c}-\sigma^{\prime} \sigma_{v}^{\prime}\right) / \sigma^{\prime} \sigma_{v}^{\prime}$ and the $O C R$. An empirical relationship was recently proposed by Zein [14] to estimate the OCR from CPT data for Sudanese fine grained soils. The soils were divided into five groups according to the friction ratio $\left(R_{f}\right)$ and the OCR was related to $\left(q_{c}-\sigma^{\prime} \sigma_{v}^{\prime}\right) / \sigma^{\prime} \sigma_{v}^{\prime}$ as given in Table 2.

The undrained soil strength $S_{u}$ was related to the strength ratio $\left(\frac{S_{u}}{\sigma_{v n c}}\right)$ of normally consolidated soils and the $O C R$ [15] by the equation:

$$
\frac{S_{u}}{\sigma_{v}^{\prime}}=\left(\frac{S_{u}}{\sigma_{v n c}}\right) O C R^{A}
$$

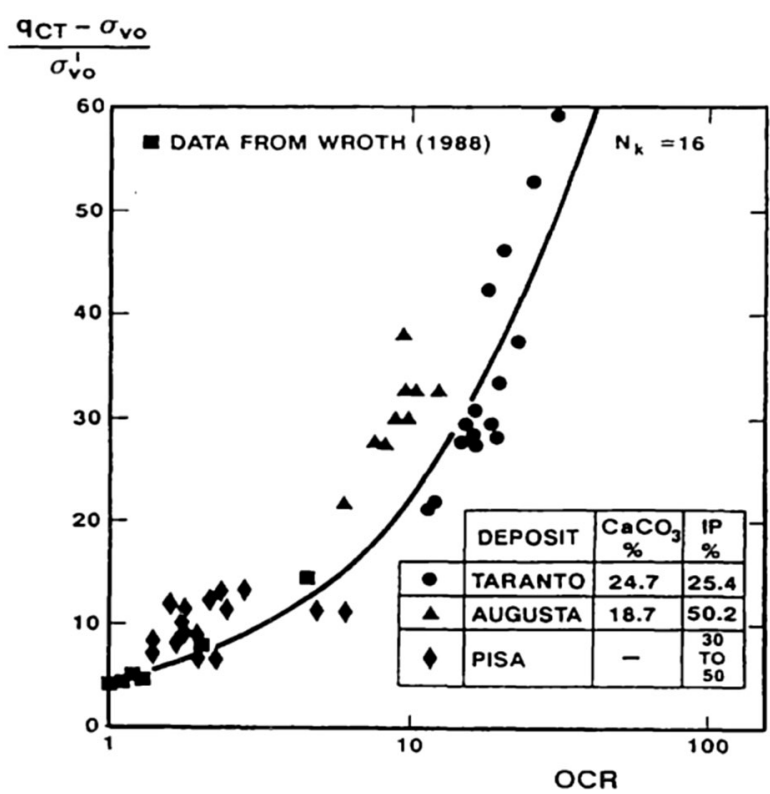

Fig. 1 Estimation of OCR from normalized net cone resistance (after [13]) 
Table 2 Prediction of the OCR of fine grained soils from CPT cone resistance

\begin{tabular}{|c|c|c|c|}
\hline Friction ratio $R_{f}(\%)$ & Best fit line equation & $R^{2}$ & Standard deviation \\
\hline Over 7.0 & $O C R=0.034\left(q_{c}-\sigma_{v}^{\prime}\right) / \sigma_{v}^{\prime}+1.230$ & 0.793 & 0.982 \\
\hline $5.0-7.0$ & $O C R=0.047\left(q_{c}-\sigma_{v}^{\prime}\right) / \sigma_{v}^{\prime}+0.728$ & 0.714 & 1.227 \\
\hline $3.5-5.0$ & $O C R=0.049\left(a_{c}-\sigma_{v}^{\prime}\right) / \sigma_{v}^{\prime}+0.56$ & 0.645 & 1.322 \\
\hline $2.0-3.5$ & $O C R=0.013\left(q_{c}-\sigma_{v}^{\prime}\right) / \sigma_{v}^{\prime}+2.102$ & 0.737 & 1.539 \\
\hline Less than 2.0 & $O C R=0.018\left(q_{c}-\sigma_{v}^{\prime}\right) / \sigma_{v}^{\prime}+1.405$ & 0.845 & 1.237 \\
\hline
\end{tabular}

$A$ is a strength rebound exponent with a value of 0.7 . The $\left(q_{c}-\sigma^{\prime} \sigma_{v}^{\prime}\right)$ and $S_{u}$ values in Eqs. (3) and (4) were normalized to effective overburden pressure to provide dimensionless parameters. The relationship shown in Fig. 2 was proposed by Schmertmann [6] between normalized undrained cohesion ratios of normally and overconsolidated clay soils and the $O C R$.

The Swedish experience suggests that $O C R$ corrections should be applied for the soil strength of clay soils obtained from CPT data. The following relationship was developed between undrained cohesion $\left(c_{u}\right)$, net cone resistance $\left(q_{t}-\sigma^{\prime} \sigma_{v}^{\prime}\right)$, empirical cone factor $N_{k t}$ and the OCR for Swedish overconsolidated clays where $q_{t}$ is the total cone resistance [16]:

$$
c_{u}=\frac{\left(q_{t}-\sigma_{v}^{\prime}\right)}{N_{k t}}+\left(\frac{O C R}{1.3}\right)^{-0.2}
$$

The soil type and stress history effects on the $q_{c}-S_{u}$ relationship were investigated for Sudanese fine grained soils with different $O C R$ values [17]. The soils were divided according to their OCR into normally to slightly consolidated $(O C R<2)$, moderately over consolidated $(2<O C R<6)$ and heavily overconsolidated $(O C R \geq 6)$. The study results showed that the $O C R$ has a significant effect on the $q_{c}-S_{u}$ relationship but no reliable correlation was revealed for the soils tested.

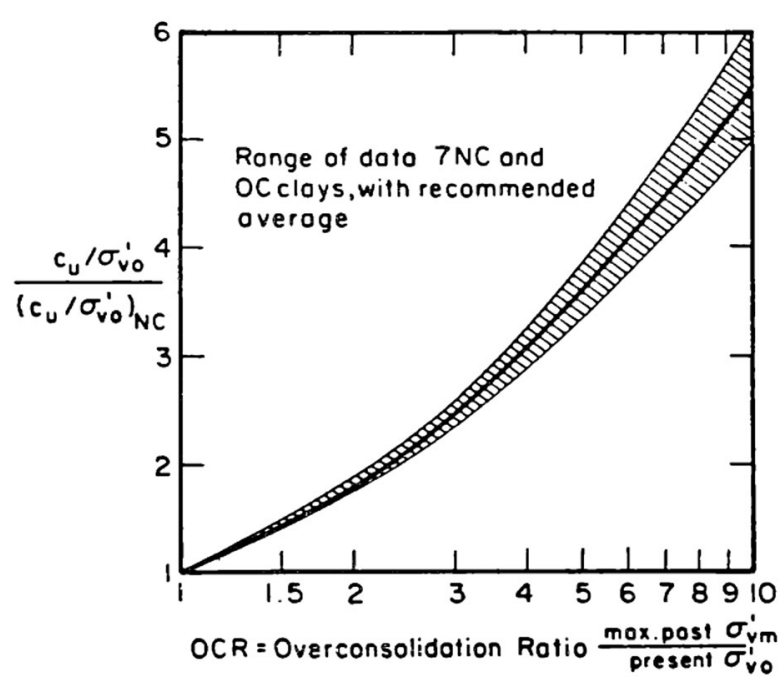

Fig. 2 Relationship of normalized undained soil cohesion and OCR (after [6]) 


\section{Soil database, techniques and methodology}

The database used in this study was obtained from the results of CPT and undrained shear strength tests performed on fine grained soils from three Sudanese states. The database pertains to low to high plastic clay and silt soil samples collected from 30 different sites, 25 in Khartoum State (central Sudan), 3 in Kordufan State (western Sudan) and 2 in Gedaref State (eastern Sudan). The soils from Khartoum state comprised alluvial stiff to very stiff clay-silt-sand mixtures. Geologically, the vast majority of the samples lie within the superficial deposits of River Nile valley in Khartoum area.

In total, 138 soil samples with liquid limit and plasticity index values plotted in Fig. 3 were used for undrained shear strength determination. About $80 \%$ of the soil samples were taken from depths above ground water table in the boreholes which indicates that they were in an unsaturated condition.

The CPT soundings were performed by a mechanical adhesion jacket cone adjacent to the borings from which the soil samples were obtained for $S_{u}$ determination. The selection of distance between the borings and CPT holes involved two opposing desires; to minimize the effects of soil failure zones and to lessen the problem of non-homogeneity of tested soil. The cone resistance $q_{c}$ and sleeve friction $f_{s}$ were measured at depth intervals of $200 \mathrm{~mm}$ and the friction ratio $R_{f}$ was computed.

The undrained cohesion $c_{u}$ and angle of internal friction $\phi_{u}$ shear strength parameters were determined from UU triaxial test results. For fully saturated soils where $\phi_{u}=0, S_{u}$ is independent of the confining pressure and is equal to $c_{u}$. For unsaturated or overconsolidated soils in which $\phi_{u}>0$, the undrained strength was computed using the method proposed by Cleveland [18] explained hereunder.

At a point on a particular plane, the undrained shear strength was expressed by the Coulomb's theory as a linear function of the normal stress at failure $\sigma_{f}$ as:

$$
S_{u}=c_{u}+\sigma_{f} \tan \varphi_{u}
$$

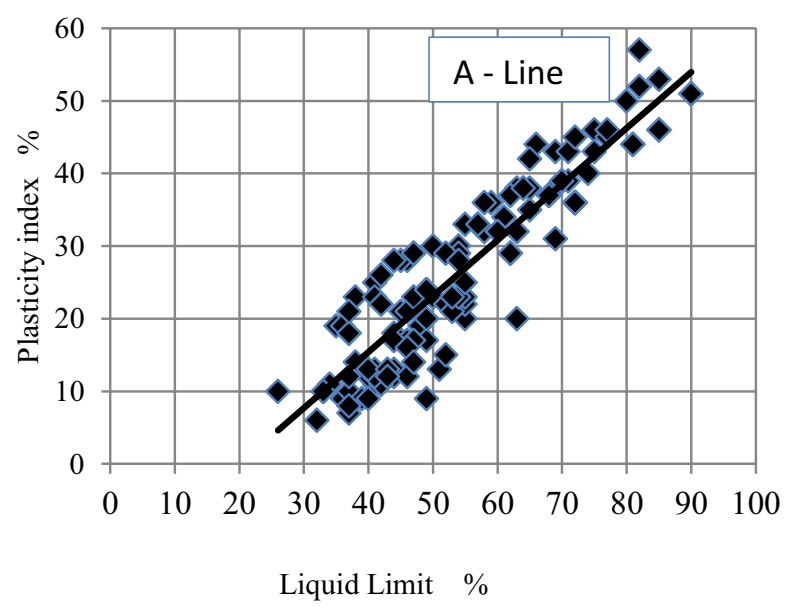

Fig. 3 Plasticity indices of studied soil types 
The normal stress $\sigma_{f}$ at failure can be related to the major and minor principal stresses $\sigma_{1}$ and $\sigma_{3}$ as:

$$
\sigma_{f}=\frac{1}{2}\left[\left(\sigma_{1}+\sigma_{3}\right)-\left(\sigma_{1}-\sigma_{3}\right) \sin \varphi_{u}\right]
$$

Dividing Eq. 7 by $\sigma_{3}$ and rearranging:

$$
\sigma_{f}=\frac{\sigma_{3}}{2}\left[\sigma_{1}\left(1-\sin \varphi_{u}\right)+\left(1+\sin \varphi_{u}\right)\right]
$$

Substituting $\sigma_{\mathrm{f}}$ value of Eq. 8 in Eq. 6, the following relationship can be derived:

$$
S_{u}=c_{u}+\frac{\sigma_{3} \tan \varphi_{u}}{2}\left[R\left(1-\sin \varphi_{u}\right)+\left(1+\sin \varphi_{u}\right)\right]
$$

The $c_{u}$ and $\phi_{u}$ values obtained from laboratory testing were substituted in Eq. (9). The minor principal stress $\sigma_{3}$ at which failure of the soil specimens occurs was assumed equal to the effective overburden pressure $\sigma^{\prime} \sigma^{\prime}{ }_{v}$ calculated down to the appropriate sample depth. The total stress ratio $\left(\sigma_{1} / \sigma_{3}\right)$, denoted by $R$ was obtained by plotting the $\left(\sigma_{1} / \sigma_{3}\right)$ ratio used for the tested specimens against $\sigma_{3}$ and then taking $R$ values from the plot when $\sigma_{3}$ is equal to $\sigma^{\prime} \nu$.

The $S_{u}$ computed according to Eq. (9) varied between 30.3 and $460 \mathrm{kPa}$ in the clay soils tested with an overall average value of $129 \mathrm{kPa}$, thus the consistency of most soils could be described as firm to very stiff with few soft and hard samples. The net cone resistance $\left(q_{c}-\sigma^{\prime} \sigma_{v}^{\prime}\right)$ varied from 0.60 to $31.0 \mathrm{MPa}$ with an overall average of 5.4 MPa, which indicate rather stiff to hard soil conditions. For the silt soils, $S_{u}$ ranged from 16 to $252 \mathrm{kPa}$ with an average of $91 \mathrm{kPa}$ whereas $\left(q_{c}-\sigma^{\prime} \sigma_{v}^{\prime}\right)$ ranged from 0.37 to $18.0 \mathrm{MPa}$ with an average of 5.17 MPa.

\section{Discussion of results}

\section{Cone factor of studied soil types}

The empirical cone factor $N_{k}$ defined herein as the $\left(q_{c}-\sigma^{\prime} \sigma_{v}^{\prime}\right) / S_{u}$ ratio was computed for the different soils and the basic statistical data is given in Table 3.

The average $N_{k}$ values varied from 35.1 to 55.6 for all soils which fall within the range of values reported by Sanglerat [19]. These average $N_{k}$ values are much higher than the reported in Table 1 for normally consolidated soft to firm saturated fine grained soils but are much lower than the 89.3 value found by Gebreselassie [20] for quaternary clay and

Table 3 Statistical analysis data of the cone factor $\mathbf{N}_{\mathbf{k}}$ for different soils

\begin{tabular}{lllll}
\hline Soil type & Sample size & $\boldsymbol{N}_{\boldsymbol{k}}$ range & Average $\boldsymbol{N}_{\boldsymbol{k}}$ value & Standard deviation \\
\hline High plastic clays (CH) & 63 & $9.9-68.9$ & 35.1 & 15.3 \\
Low plastic clays (CL) & 23 & $6.6-120$ & 43.9 & 22.8 \\
All clay soils & 86 & $6.6-120$ & 37.5 & 18.9 \\
High plastic silts (MH) & 30 & $13.2-68.4$ & 36.4 & 13.7 \\
Low plastic silts (ML) & 22 & $9.2-76.8$ & 55.6 & 18.2 \\
All silt soils & 52 & $9.2-76.8$ & 44.1 & 17.7 \\
\hline
\end{tabular}


clay stone in southern Germany. It appears that the low $N_{k}$ values reported elsewhere pertain to fully saturated and normally consolidated fine grained soil samples. The $N_{k}$ values obtained are in close agreement with and confirm the 35 figure reported by Ismail and Zein [21] for Sudanese highly plastic clay and silt soils. Also, the average $N_{k}$ values for the low plastic soils compare favorably with those reported by Hassan [17] for similar soils.

Generally, for most soil types considered in this study the $N_{k}$ values were higher than those reported in some other countries. Apart from the differences in the nature, testing techniques and geological history the higher $N_{k}$ values may be attributed to the insitu conditions prevailing when the soils were tested. As stated earlier most soil samples considered in this study were in a naturally unsaturated condition. Suction stresses normally develop in unsaturated soils with magnitudes depending on their moisture condition. It is well known that the higher the soil suction the higher would be the shear strength and cone resistance values. Therefore, it seems difficult to compare the $N_{k}$ values of unsaturated soils with those deduced for saturated soils.

Furthermore, the $N_{k}$ value of cohesive soils appears to be dependent on the stiffness which can be roughly assessed in terms of the soil resistance to cone penetration measured during CPT testing. To investigate how the $\left(q_{c}-\sigma^{\prime} \sigma_{v}^{\prime}\right)$ value may affect the $N_{k}$ values the soil database were arbitrarily grouped in two categories with $\left(q_{c}-\sigma^{\prime} \sigma_{v}^{\prime}\right)$ values lower and higher than $5 \mathrm{MPa}$. A comparison of simple statistical data of $N_{k}$ values pertaining to the two soil groups is given in Table 4 .

There is a difference of 25.3 in the values of average $N_{k}$ pertaining to the soil groups of the lower and upper $\left(q_{c}-\sigma^{\prime} v\right)$ ranges. For most soils having $\left(q_{c}-\sigma^{\prime} \sigma_{v}^{\prime}\right) \leq 5 \mathrm{MPa}$ the $N_{k}$ values compare well with those proposed in some previous studies (Table 1) for soft to firm saturated clays. Also there is a good agreement between the $N_{k}$ values obtained for soils with $\left(q_{c}-\sigma^{\prime} \sigma_{v}^{\prime}\right)>5 \mathrm{MPa}$ and those revealed for similar soils in Sudan [17] and Nigeria [22]. Exceptionally high $N_{k}$ values were indicated in few very stiff or hard clay and silt soil samples. It is believed that these samples had suffered great disturbance caused by their high resistance to sampling tube penetration that had lead to significant shear strength reductions and thus obtaining very high $N_{k}$ values.

\section{Correlation of $S_{u}$ and $\left(q_{c}-\sigma^{\prime} \sigma_{v}^{\prime}\right)$ for Sudanese soils \\ Direct Relationships}

Several attempts were made to establish a direct relationship between $S_{u}$ and $\left(q_{c}-\sigma^{\prime} \sigma_{v}^{\prime}\right)$ based on analysis of the database pertaining to all soil samples but without success. No meaningful relationship trends were observed when the two variables were plotted of against each other and the scatter of data points was very significant. This indicates that a simple correlation cannot be developed between $\left(q_{c}-\sigma^{\prime} \sigma_{v}^{\prime}\right)$ and $S_{u}$ for all soil types and

Table 4 Variation of $N_{k}$ with measured $\left(q_{c}-\sigma_{v o}\right)$ values

\begin{tabular}{llll}
\hline Measured cone resistance $\mathbf{q}_{\mathbf{c}}$ & $\boldsymbol{N}_{\boldsymbol{k}}$ range & Average $\boldsymbol{N}_{\boldsymbol{k}}$ value & Standard deviation \\
\hline$\left(q_{c}-\sigma_{v 0}\right) \leq 5 \mathrm{MPa}$ & $6.6-72.6$ & 30.5 & 14.97 \\
$\left(q_{c}-\sigma_{v 0}\right)>5 \mathrm{MPa}$ & $9.9-120$ & 55.8 & 27.40 \\
\hline
\end{tabular}


conditions as the relationship is influenced by several factors such as the testing methodology, soil type and stress history [6]. This finding confirms the conclusion of previous studies that the empirical cone factor $N_{k}$ is not a simple constant but varies significantly from site to site.

\section{Indirect relationships}

As suggested in some studies [7, 8], indirect relationships may be developed between $S_{u}$ and $\left(q_{c}-\sigma^{\prime} \sigma_{v}^{\prime}\right)$ by incorporation of the plasticity index PI and overconsolidation ratio $(O C R)$ as parameters indicative of the soil type and stress history. The possibility of developing a reliable correlation of $S_{u}$ and $\left(q_{c}-\sigma^{\prime} \sigma_{v}^{\prime}\right)$ based on both parameters was investigated for the Sudanese soils as discussed below.

Relationship between $N_{k}$ and PI To investigate that a reliable relationship exists as claimed by some previous authors between the cone factor $N_{k}$ and plasticity index PI, the two variables were plotted against each other for all soil types as shown in Fig. 4. As may be noted from this figure the data scatter is so significant such that $N_{k}$ values varied widely from less than 10 to higher than 100 for soils with equal PI. This indicates that for the Sudanese soils tested no correlation can be developed to enable estimating the $N_{k}$ from the PI.

$S_{u}-\left(q_{c}-\sigma^{\prime} v\right)$ Relationships based on OCR To study the effect of OCR on the $S_{u}-\left(q_{c}-\sigma^{\prime} \sigma_{v}^{\prime}\right)$ relationship the soil database was firstly divided into clays and silts subgroups to account for the type variability in analysis. Kulhawy and Mayne [23] indicated that the normalization of the $S_{u}$ values to $\sigma^{\prime} \sigma_{v}^{\prime}$ provides a form which is mode dependent and reliant on initial stress state, strain rate, direction of loading, degree of fissuring, and other factors. For undrained cone penetration analysis, the $\left(q_{c}-\sigma^{\prime} \sigma_{v}^{\prime}\right)$ is often related to undrained strength $S_{u}$ through the factor $N_{k}$ and thus the values of $\left(q_{c}-\sigma^{\prime} \sigma_{v}^{\prime}\right)$ and $S_{u}$ normalized to effective overburden pressure $\sigma^{\prime}{ }_{v}$ can be related in the same manner. The values of $\left(q_{c}-\sigma^{\prime} \sigma_{v}^{\prime}\right)$ were also normalized to $\sigma^{\prime}{ }_{v}$ to have a dimensionless parameter similar to $S_{u} / \sigma^{\prime} \sigma_{v}^{\prime}$ ratio.

Various approaches of database analysis have been attempted to develop a suitable mathematical model based on the soil OCR which describes the correlation of

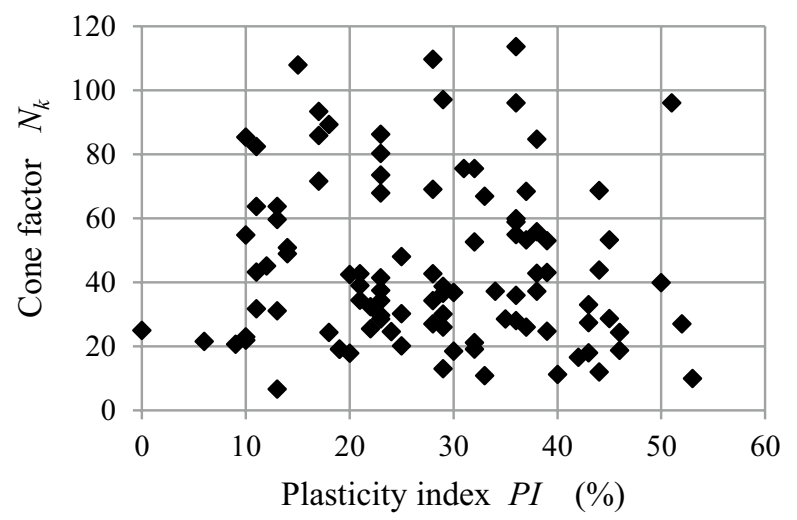

Fig. 4 Cone factor $N_{k}$ versus plasticity index PI for Sudanese soils 
normalized $\left(q_{c}-\sigma^{\prime} \sigma_{v}^{\prime}\right)$ and $S_{u}$. It was revealed from analysis that the correlation of normalized $\left(q_{c}-\sigma_{v}^{\prime}\right)$ and $S_{u}$ values and the OCR can best be expressed by the general equation:

$$
\frac{\left(q_{c}-\sigma_{v}^{\prime}\right)}{\sigma_{v}^{\prime}}=A\left(\frac{S_{u} O C R}{\sigma_{v}^{\prime}}\right)+B
$$

$A$ and $B$ are constants depending on soil type. The data pertaining to the mathematical terms in Eq. (10) were plotted as shown in Figs. 5, 6 and 7 to determine the constants A and $B$ which represent the slope and the $y$-intercept of the best fit lines for clay soils, silt soils and all soils respectively.

The clay soils exhibited a best fit line slope (constant A) equals to 6.0 Eq. (11) which is much lower than the 13.9, Eq. (12) revealed for the silty soils. This indicates that the $\left(\frac{S_{u} O C R}{\sigma_{v}^{\prime}}\right)$ term is more sensitive to $\frac{\left(q_{c}-\sigma_{v}^{\prime}\right)}{\sigma_{v}^{\prime}}$ variations in the silts than in the clay soils. On the other hand, the clay soils indicated a best fit line y-intercept (B) of 8.1 which is much lower than 20.7 derived from analysis for the silt soils.

The trends shown in Figs. 5, 6 and 7 indicate that there is a sound line relationship between the terms $\frac{\left(q_{c}-\sigma_{v}^{\prime}\right)}{\sigma_{v}^{\prime}}$ and $\left(\frac{S_{u} O C R}{\sigma_{v}^{\prime}}\right)$ for each soil group. The relationships derived from linear regression analysis are given by Eqs. (11) and (12) for the clay and silt soils respectively.

$$
\begin{aligned}
& \frac{\left(q_{c}-\sigma_{v}^{\prime}\right)}{\sigma_{v}^{\prime}}=6.0\left(\frac{S_{u} O C R}{\sigma_{v}^{\prime}}\right)+20.7 \\
& \frac{\left(q_{c}-\sigma_{v}^{\prime}\right)}{\sigma_{v}^{\prime}}=13.9\left(\frac{S_{u} O C R}{\sigma_{v}^{\prime}}\right)+8.1
\end{aligned}
$$

The goodness of the above relationships was assessed by the coefficient of determination $\left(R^{2}\right)$ achieved from the regression analysis. $R^{2}$ values of 0.79 and 0.81 were obtained

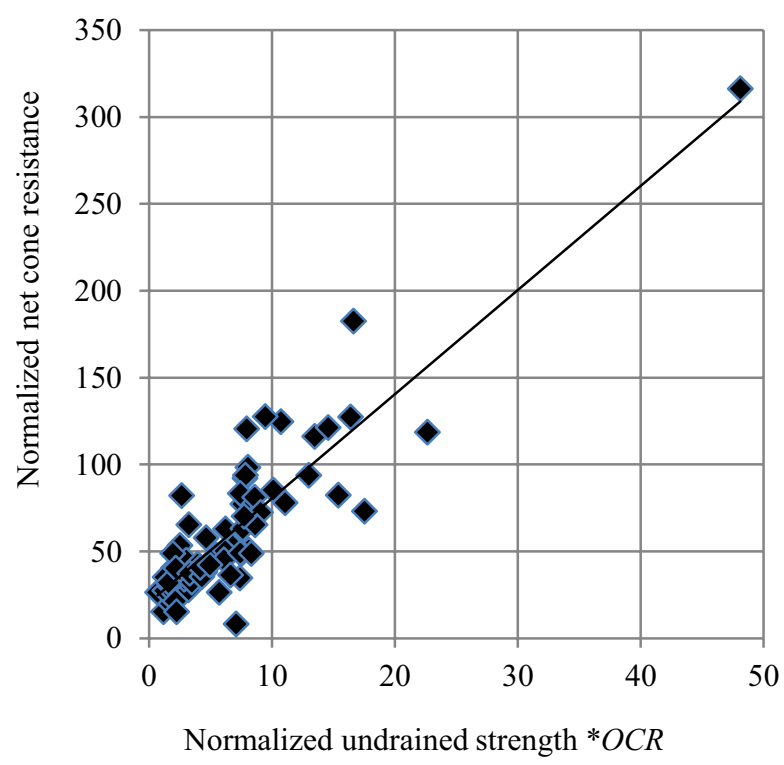

Fig. 5 Relationship of normalized net cone resistance and undrained strength for clay soils 


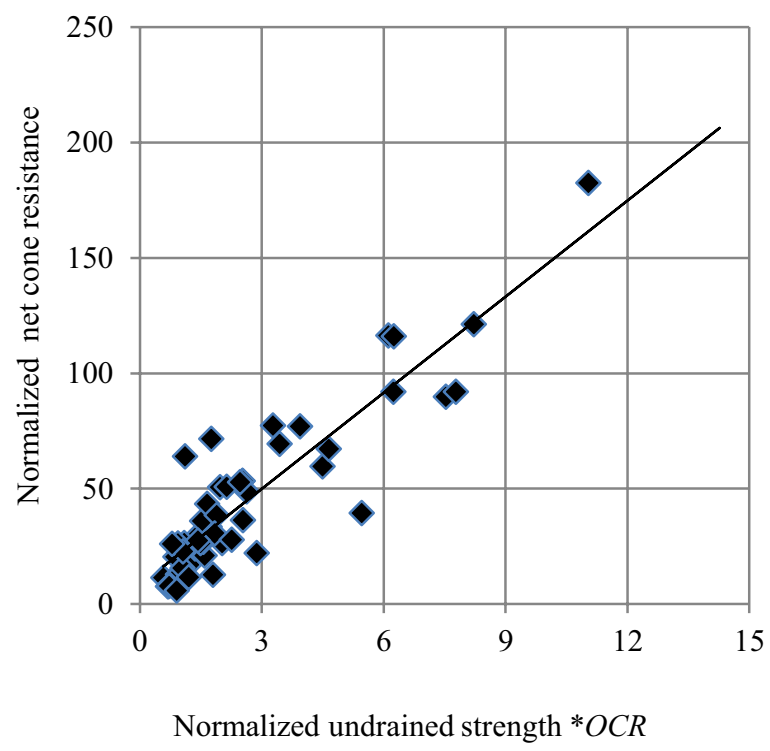

Fig. 6 Relationship of normalized net cone resistance and undrained strength of silt soils

for the clay and silt soil types respectively. A relationship of lower correlation $\left(R^{2}=0.74\right)$ was obtained as given by Eq. (13) for database pertaining to all samples which reflects the soil type effect.

$$
\frac{\left(q_{c}-\sigma_{v}^{\prime}\right)}{\sigma_{v}^{\prime}}=6.23\left(\frac{S_{u} O C R}{\sigma_{v}^{\prime}}\right)+20.94
$$

The normalization of the $S_{u}$ and $\left(q_{c}-\sigma^{\prime} \sigma_{v}^{\prime}\right)$ to $\sigma^{\prime} v$ has lead to a better matching of the soil parameters as indicated by the fairly high $R^{2}$ values achieved from database analysis. Very low $R^{2}$ values $(<0.35)$ were obtained when the database were analyzed without normalization.

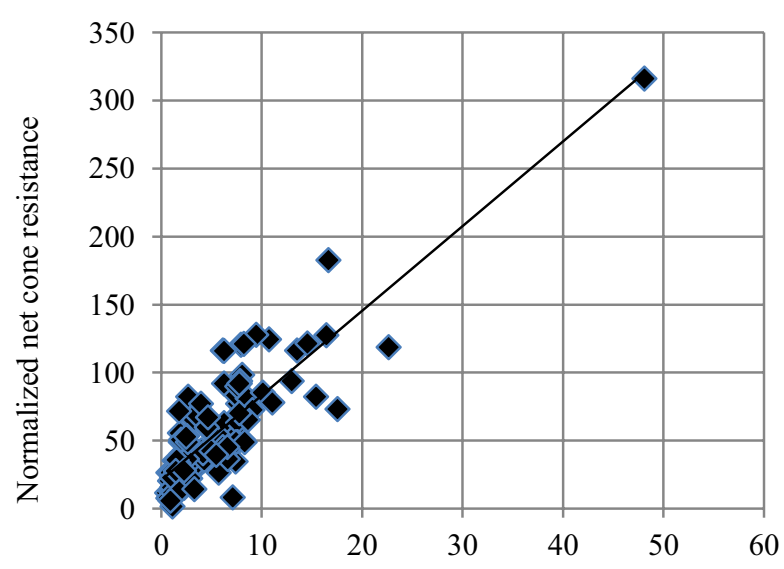

Normalized undrained strength * $O C R$

Fig. 7 Relationship of normalized net cone resistance and undrained strength for all soils 
Therefore, the study results show that reliable relationships may be established between undrained shear strength and net cone resistance parameters when the soil type and stress history effects are considered in analysis. In the absence of soil data determined from conventional triaxial testing Eqs. (11) and (12) may be used estimate $S_{u}$ from known values of $q_{\mathcal{c}} O C R$ and $\sigma^{\prime} \sigma_{v}^{\prime}$. The $O C R$ values required for applying these equations may be either estimated from Table 2 for Sudanese soils or from the Robertson's chart shown in Fig. 1 . Though high $R^{2}$ coefficient values were achieved from analysis the developed relationships are of empirical nature and should be applied with care, until they are supported by additional data in future research works.

\section{Conclusions}

The following conclusions may be drawn on the correlation of undrained shear strength $\mathrm{S}_{\mathrm{u}}$ and CPT cone resistance $\mathrm{q}_{\mathrm{c}}$ for Sudanese clay and silt soils:

a. The empirical cone factor $N_{k}$ relating the net cone resistance $\left(q_{c}-\sigma^{\prime} \sigma_{v}^{\prime}\right)$ to undrained strength $S_{u}$ varied over a relatively wide range with average values of 37.5 and 44.1 for the clay and silt soils studied.

b. A direct relationship cannot be established between $\left(q_{c}-\sigma^{\prime} \sigma_{v}^{\prime}\right)$ and $S_{u}$ for soils of different types and characteristics as their values are influenced by several factors. The effects of certain parameters such as soil type and stress history should be considered in studying such a relationship.

c. For a given soil $N_{k}$ seems to depend on the moisture condition and degree of stiffness prevailing in the field during testing. Interpretation of $\mathrm{CPT}$ and shear strength data is different for saturated and unsaturated soils and this makes comparison of the $N_{k}$ values difficult. Soils with higher cone resistance values tend to give higher $N_{k}$ values than those with lower values.

d. A rigorous analysis was carried out to develop a mathematical model describing the relationship between $\left(q_{c}-\sigma^{\prime} \sigma_{v}^{\prime}\right)$ and $S_{u}$ which takes into account soil type and stress history factors.

e. Reliable relationships have been developed to estimate the undrained shear strength from CPT cone resistance for fine grained soils with different OCR values. The developed relationships should be applied with care in practice until they are supported by further data.

Competing interests

The author declares that he has no competing interests.

\section{Publisher's Note}

Springer Nature remains neutral with regard to jurisdictional claims in published maps and institutional affiliations.

Received: 20 July 2016 Accepted: 20 April 2017

Published online: 05 May 2017

\footnotetext{
References

1. De Beer E (1977) Static cone penetration testing in clay and loam. In: Proceedings Sonder symposium, Fugro, pp $15-23$

2. Terzaghi K (1943) Theoretical soil mechanics. Wiley, New York
} 
3. Skempton AW (1951) "The bearing capacity of clays". In: Proceedings British Building Research Congress, Vol 1, pp 180-189

4. Ladanyi B (1967) "Deep punching of sensitive clays". In: Proceedings 3rd Panamerican American Conference on soil mechanics \& Foundation Engineering, pp 333-546

5. Teh Cl (1987) "An analytical study of the cone penetration test"Ph.D. Thesis, University of Oxford, Hertford College, Oxford

6. Schmertmann J (1978) "Guidelines for cone penetration test performance and design" US Federal Highway Admin., Report FHWA-TS-78-209, p 145

7. Skempton AW (1957) "Discussions of the planning and design of the new Hong Kong Airport, vol 7". In: Proceedings Institute of Civil Engineers, London, pp 305-307

8. Mayne PW (2007) "Cone Penetration Testing" NHCRP Synthesis 368, TRB

9. Novobasi PA (2013) Estimation of undrained shear strength of soil using cone penetration test. Int J Sci Eng Res 4(9):409-419

10. Rémai Z (2013) Correlation of undrained shear strength and CPT resistance. Period Polytech Civ Eng 57(1):39

11. Mayne PW, Kemper JB (1988) Profiling OCR in stiff clays by CPT SPT. Geotech Test J 11:139-147

12. Powell Jl, Quarterman RT, Lunne T (1988) Interpretation and use of the Piezo-cone Test in UK clays. In: Proceeding of the Geo-technology Conference on penetration testing, London, UK, pp 151-156

13. Robertson PK (1990) Soil classification using the cone penetration test. Can Geotech J 27(1):151-158

14. Zein AKM (2015) Use of static cone penetration test for evaluation of over-consolidation ratio of some Sudanese cohesive soils. J Build Road Res 19:1-15

15. Mayne PW (1986) CPT indexing of in-situ OCR in clays. In: Proceedings use of in-situ tests in geotechnical engineering, ASCE, VPI, Blacksburg, pp 780-793

16. Larsson R, Sällfors G, Bengtsson P-E, Alén C, Bergdahl U, Eriksson L, (2007b) Utvärderingavskjuvhållfasthet i kohesionsjord.Statensgeotekniskainstitut, SGl,Linköping Information Nr 3, p 28

17. Hassan M (2004), Evaluation of undrained shear strength from CPT for local fine grained soils unpublished M.SC. Thesis, BRRI, University of Khartoum, Khartoum

18. Cleveland EP (1971) "Use of Dutch cone penetration test for soil exploration in Kentucky" M.Sc. Thesis, University of Kentucky, Lexington

19. Sanglerat G (1972) The penetrometer and soil exploration, developments in geotechnical engineering. Elsevier Scientific Publishing Co., New York

20. Gebreselassie B (2003) Experimental, analytical and numerical investigations of excavations in normally consolidated soft soils Ph.D. Thesis, University of Kassel, Kassel

21. Ismail HA, Zein AKM (1987) Prediction of undrained shear strength and SPT using the static CPT data. In: Proceedings 9th regional African Conference on SMFE, Lagos, 1987, pp 185-192

22. George R, Otoko, IsoteimFubara-Manuel, Igwagu M, Edoh C (2016) "Empirical cone factor for estimation of undrained shear strength" EJGE, (21.18), pp 6069-6076

23. Kulhawy FH, Mayne PW (1990) Manual on estimating soil properties for foundation design Report EL-6800, Electric Power Research Institute, Palo Alto, p 306

24. Abdel Rahman I (2007) Correlation of cone resistance with undrained shear strength for clay soils. Report for partial fulfillment of M.Sc. in Geotechnics, Civil Engineering, UTM, Skudai

25. Chen CS (2001) Evaluating undrained strength of Klang Clay from cone penetration test. In: Proceedings International Conference on insitu measurement of soil properties and case histories, 2001, Indonesia, pp 141-148

26. Terzaghi K, Peck R, Mesri G (1996) Soil mechanics in engineering practice, Third Edition edn. Wiley, New York

27. Hong S, Lee M, Kim J, Lee W (2010) Evaluation of undrained shear strength of Busan clay using CPT. In: Proceedings of 2nd International symposium on cone penetration testing, CPT'10, online, paper No. 2-23

\section{Submit your manuscript to a SpringerOpen ${ }^{\circ}$ journal and benefit from:}

- Convenient online submission

Rigorous peer review

- Immediate publication on acceptance

- Open access: articles freely available online

- High visibility within the field

- Retaining the copyright to your article

Submit your next manuscript at $>$ springeropen.com 